\title{
Using Web-based Intelligent Tutoring Systems in Teaching Physics Subjects at Undergraduate Level
}

\author{
Mustafa Erdemir \\ Department of Mathematics and Science Education, Education Faculty, Kastamonu University, Turkey
}

Copyright $\mathrm{C} 2019$ by authors, all rights reserved. Authors agree that this article remains permanently open access under the terms of the Creative Commons Attribution License 4.0 International License

\begin{abstract}
The aim of the study is to draw attention to the importance of using web-based intelligent tutoring systems (WBITS), which have emerged as a result of artificial neural networks and technological developments (communication technology), in the teaching of physics subjects. A WBITS is an intelligent tutoring system that exhibits behavior similar to that of a teacher in the traditional educational process (classroom education), offers a flexible teaching process, defined according to user preferences, and adaptable for a specific purpose. WBITSs make important contributions to distance education and classroom education processes, because they can be used online and offline. The importance of using WBITSs in teaching physics at undergraduate level was subsumed under five headings: i). Developments in technology and artificial neural networks and the interest of young people in technology have made it important to use WBITSs in undergraduate physics education. ii) The use of WBITSs has become important in following scientific developments in traditional (classroom) physics education and eliminating problems related to individual perception capacity and insufficient class hours. iii). Online (remote) access to physics subjects via WBITSs contributes to equality of opportunity in education. iv). More time can be devoted to practice and the discussion of deeper (advanced) subjects in the classroom when basic physics subjects are taught at undergraduate (university) level using WBITSs. v). Limitations in distance physics education can be reduced using WBITSs.
\end{abstract}

Keywords Web-based Intelligent Tutoring Systems, Physics Education, Distance Education

\section{Introduction}

Traditional classroom education is the main type of teaching and training activities. Technological tools and equipment are used to support classroom education or to provide education to those, who have not received education for various reasons. As the use of technology and communication tools in educational activities becomes widespread, the areas of use are extended. The use of technology and communication tools in education heightens the expectations of educational institutions and organizations. Technological developments have led to changes in educational situations, the reorganization of learning environments, and the development of technology-based instructional systems. Computer and internet technology is the leading technological tool used in education. Accessing global resources via the internet increases the interest in online learning environments and brings great convenience to teachers and learners. Global cooperation in education and access to a variety of rich information resources without time and space constraints offer flexible educational opportunities.

The use of computer and communication technologies in education has introduced learning environments and learning systems that can be adapted for different purposes. Software engineering, communication technology, artificial neural networks, and artificial intelligence developments have been effective in establishing computer-based intelligent tutoring systems. Intelligent tutoring systems (ITS) have been developed as a result of research in the field of artificial intelligence and education [1]. ITSs offer adaptability to the intended purpose and learners' learning skills. They also help promote cooperation between business and universities, thereby contributing to improving the quality of higher education. The use of intelligent network systems in the fields of education, industry, agriculture, construction, transport, communication, and computer facilitates the development of institutions [2].

\subsection{Web-based Intelligent Tutoring Systems}

A WBITS can be considered as internet-based (distance education) intelligent tutoring systems (ITS). It means 
accessing course contents, prepared using offline (nonsynchronous) ITS, via the internet. Developments in computer and communication technology have created new opportunities for distance education; thus, the use of web- and computer-based education systems in distance education has become widespread. New systems have been designed and tested in distance education in parallel with technical and social developments throughout history [3]. Moore and Kearsley [4] subsume distance education under five categories in line with technological developments as follows: by letter, radio and television, open universities, teleconference, and internet/web-based education. The subsets of internet-based distance education consist of e-learning, online learning, internet/web-based education, and computer-based learning [5].

Web-based course contents provide flexibility and convenience, as they are accessible without cost and time and space constraints. Flexibility and cost advantages in education increase the importance of web-based education day by day [6]. The use of web-based education by many people makes it more advantageous than classroom education although web-based education has limitations such as one-to-one instruction, exams, and assignments [7]. UNESCO [8] emphasizes that easy access to information via the internet is important for efficient economic growth in educational institutions. It is also important for working people and lifelong learning. Web-based learning systems play an important role in self-learning situations especially for working people [9].

Internet/web-based education has negative aspects as well as positive aspects. Students are unlikely to complete and succeed in web-based courses compared to traditional education. Doherty [10] notes that web-based courses are more attractive to busy people; however, they are more likely to fail. Learners' interest in distance courses is 20 to $10 \%$ less than their interest in face-to-face courses [11]. Research has been carried out on student distributions, learning styles, one-to-one communication, and socialization to eliminate the limitations of web-based education.

ITSs consist of three components: computer systems (programming techniques, graphics, human-computer interaction, and simulation), artificial intelligence (information display, reasoning, machine and learning, and expert systems), and instructional support (cognitive science, pedagogy, psychology, and education sciences) [12]. ITSs are computer-based instruction systems that exhibit teacher-like behavior and can be used in classroom education and distance education processes. In addition, they support classroom education, offer opportunities for those without the opportunity to study, and provide purpose-oriented learning environments, thereby contributing to academic developments. ITSs eliminate shortcomings of classroom education, support lifelong learning, facilitate long-distance learning, and provide a learning environment based on individual learning styles. Canfield [13] described an ITS as an adaptable system that recognizes learners' knowledge and skills and provides feedback about the presentation of new topics. Significant learning outcomes have been achieved in educational processes carried out through ITSs [14, 1, 12, 15, 16, 17] Course contents can be presented as computer-based (online) course contents, and can be uploaded on a server and accessed offline through ITSs. In WBITSs, course contents with intelligent design are accessed via the internet. In WBITSs, course contents are accessible anywhere and anytime via a computer and the internet.

\subsection{Intelligent Tutoring Systems Used in Physics Education}

The tutoring system called "Andes physics tutoring system" identifies errors in the steps of solving physics problems and provides clues about what the next step is [18].

The Andes physics tutoring system is an assessment-based interactive physics system to create a computer-based learning environment in physics education and to determine how formative questions are used [19].

The Virtual Physics System (ViPS) is a virtual learning environment developed to teach physics subjects [20].

Albacate [21] developed an ITS for teaching physics concepts.

Chakraborty et al [22] developed an ITS based on the storage of physics images in the long-term memory.

Chi and Vanlehn [23] developed an ITS to bridge the gap between successful and unsuccessful students while teaching physics subjects.

Mills and Dalgarno [24] developed a game-based ITS for learning Newtonian Physics concepts.

Stathacopoulou, Magoulas ve Grigoriadou developed an ITS for learning the vertical movement.

Within the scope of the doctoral thesis entitled "Integration and Application of an Internet-based Intelligent Tutoring System to Physics Education", a WBITS, which addresses the physics subjects of work, energy, and energy conservation, was designed and the academic performance and retention of preservice teachers who learned offline using the system were investigated [26].

\subsection{The Importance of Using WBITSs in Physics Education}

The reasons for the importance of using WBITSs in physical education were subsumed under five headings. The findings and results of the study were presented under these headings.

1. The importance of using WBITSs in teaching physics subjects at university level, 
2. The importance of using WBITSs in teaching physics subjects to support classroom educational and instructional processes and eliminate shortcomings caused by limited class hours,

3. The importance of using WBITSs to access physics topics without time and space constraints and offer equal training opportunities,

4. The importance of using WBITSs in teaching basic physics subjects at university level to devote greater attention to current topics and increase practical (experimental) activities through the teaching of theoretical subjects via the system, and

5. The importance of using WBITSs in teaching physics subjects offline (remote) to control learning processes.

\section{Methods}

This study is an opinion paper. In an opinion paper, a topic is discussed in line with personal thoughts, beliefs, or feelings and the claim about that topic is supported with facts, statistics, real-life examples, and published research studies (American Public University System," APUS") [27]. The findings were obtained by using the outcomes of the researcher's doctoral thesis entitled "Integration and Application of an Internet-based Intelligent Tutoring System to Physics Education" [26], and published information and studies on distance education and ITSs.

\section{Findings}

Apropos of the importance of using WBITSs in physics education, the findings were subsumed under five headings in line with the researcher's personal experiences of WBITSs and published information and studies.

\subsection{The Use of Intelligent Tutoring System (ITS) in the Teaching of Physics Subjects}

ITSs are formed through the combination of computer systems, artificial intelligence and teaching support. Computer systems consist of computer software and hardware directed to a specific purpose. Artificial intelligence is made up of information and software that try to do the works of human mind. Teaching support consists of pedagogical techniques. In ITSs used in the teaching of subjects, course content is presented according to the programmed teaching method. In the teaching of physics subjects, the course content is organized according to the programmed teaching method. Course content is presented according to the principles of the programmed teaching. Behaviours that are similar to the teacher's behaviours, demonstrated in the teaching process and carried out according to the programmed teaching method in the classroom can be created with ITS. The Intelligent tutoring process used in teaching physics subjects with programmed instruction is shown in the diagram 1 below.

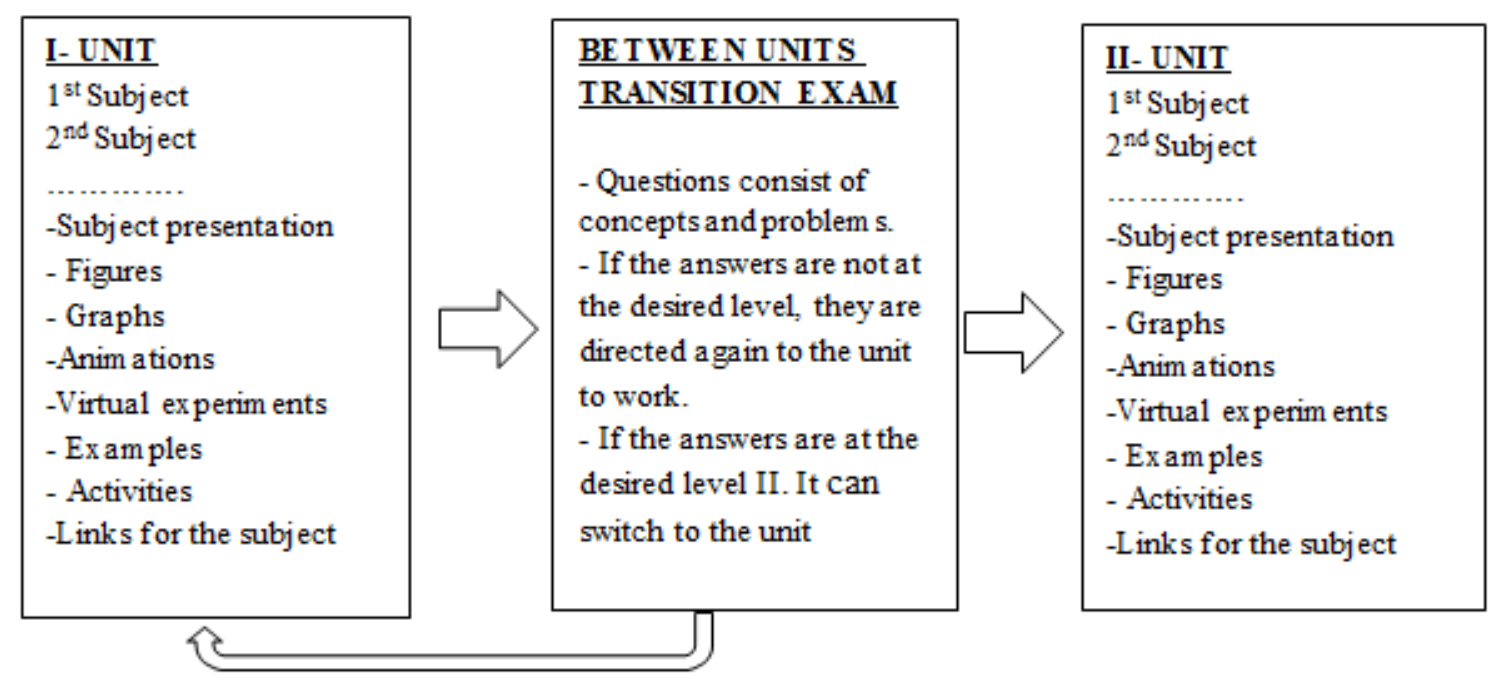

Diagram 1. Transition between the units 
The smartness characteristics of the intelligent tutoring system (ITS): In the diagram 1, the transition between two units prepared to teach physics subjects is shown. The smartness characteristics of ITS can be listed as follows according to the diagram 1. In the learning process, the computer screen is used as the interface.

1. The subject content is uploaded to ITS in compliance with computer-based course content in such a way as to include subject presentation, figures, graphs, animations, virtual experiments, examples and activities related to the subject and related links are given at the end of the subject.

2. The student starts studying from the first subject. There is a required time period to watch each page. During this time period, it is not allowed to switch to another page or subject. When the time period to watch is completed, the next page is opened for the student to study.

3. After properly watching animations, virtual experiments and many examples, activity pages of the related subject are opened. The activity pages include problems, gap filling, concept matching, and finding the correct answer activities. Whether their responses to the activities are correct or false are immediately reported to students through feedbacks.

4. Without doing the end-of-unit activities, students cannot take "between units transition exam". That is, the exam page does not open.

5. The "Between units transition exam" is time limited and consists of concepts and problem questions including the subjects. Each question is linked to a subject over the system. Questions are multiple-choice, yes-no and concept comparison questions.

6. If the responses given by the student taking the transition exam are not at the desired level, ITS directs the student to the related subjects on the basis of the questions to which wrong answers are given. The student who is lacking the required knowledge revises for the subject and then gains the right to take the between-units transition exam. If the student does not revise for the subjects he/she has been directed to, the system does not allow him/her to take the between-units transition exam. Whether the student has studied or not is determined on the basis of meeting the requirement of watching the page in the given period of time.

7. When the students having completed the revision of the missing subjects take the "between-units transition exam", if his/her answers are found at the desired level, then the subjects of the next unit $\left(2^{\text {nd }}\right.$ Unit) are opened for studying. The learning and passing conditions of the first unit hold true for the second unit.
Opportunities provided by intelligent tutoring systems for the teacher (field expert): Construction of the subjects, determination of the contents, and preparation of the examples, animations, visual experiments, activities and between-units transition exam questions are the responsibility of the teacher. The teacher also decides on the length of the time period allocated to page watching and the scoring of the transition exam and whether the student is qualified enough. The teacher's criteria are uploaded to the system and the system conducts the learning process on the basis of these criteria. An Intelligent tutoring system can be personal or can be used over the computers connected to each other in a local area network (LAN) or in a wide area network (WAN). When the student uses ITS over a computer connected to LAN and WAN, the system provides the following opportunities for the teacher.

1. Can see the student's time of watching pages in the learning process and time of entry to and exist from the system.

2. Can watch the false and correct answers given to the activities and the between-units transition exam questions.

3. Can see which page the student has watched or not.

4. Can make comments on and suggestions for the activities done by the student if there is an internet connection of the computer where ITS is loaded.

Opportunities provided by intelligent tutoring system (ITS) for the student: The system provides the following opportunities and possibilities for the student in the learning process.

1. Provides the opportunity of learning through the programmed learning method suitable for the student's skill of perception and learning.

2. As the system is computer-based (there is no page limit), it provides rich content for the subject (problems, examples, animations, virtual experiments, links to the related subject).

3. The student can reach the course content without time and space limitation over ITS.

4. When the student exists and then re-enters the system, the system remembers the last page studied.

5. Immediate feedback is given about the correctness of the responses to the activity problems.

6. At the end of the exam, the student is informed about his/her false answers of the subjects through feedbacks. Moreover, as each question is linked to a subject, it facilitates the determination of the problematic subjects and directs the students towards revising for the subject.

7. In ITS, the student can be engaged in the learning process by determining his/her own phase of learning.

8. The student has a navigation adaptation between the studied units and subjects. 


\subsection{The Use of Web-based Intelligent Tutoring System (WBITS) in the Teaching of Physics Subjects}

WBITS refers to having access to STS through the internet. Depending on their intended purpose, ITSs can be used as both computer-based and internet-based. Their internet-based use is called as WBITS. For the use of WBITS over the internet, it should be loaded to a host under a domain name. The student who wants to use the system logs in the system over the internet and gets subscribed and forms his/her user name and password. By using the user name and password, he/she can have access to the course content including physics subjects anywhere where there is a computer and internet connection asynchronously.

Internet-based intelligent tutoring systems (WBITSs) have advantages over computer-based Intelligent tutoring systems. As WBITS is over the internet, it is possible to reach it from different locations. When the student wants to revise for the previous subjects, he/she can immediately reach them. Using relevant links, information on the subject is instantly accessible. The teacher can follow students over WBITS from anywhere where there is an internet connection without time and space restrictions. The teacher informs the student on the internet and can comment on the activity pages. WBITS rids the student and the teacher of being dependent on the place for learning. A doctoral study was conducted on the use of WBITS in the teaching of physics subjects. The academic achievement of the students using WBITS was found to be higher than that of the students instructed in the classroom. The students studying the physics subjects on the system stated that WBSTS led to positive learning outcomes. On the other hand, they stated that there is a problem of interaction with peers and that there are some internet connection problems [26].

\subsection{Using WBITSs in Teaching Physics Subjects at University Level}

Developments in communication and computer technology affect all segments of society and increase expectations as to web- and computer-based learning situations. In 2018, the number of internet users in the world rose $7 \%$ to 4.021 billion [28]. 59.6\% of the Turkish population use computers and $72.9 \%$ use the internet [29]. The widespread use of the internet and computers worldwide and in Turkey has led to heightened expectations and demands in the field of education. In addition, the use of computers and communication technology in educational activities, economic benefits, and access to global education resources have been added to these expectations. Today, there is a need for new teaching techniques and skills to satisfy the demands and expectations for teaching physics subjects, as in every field of science.

WBITSs offer self-learning opportunity for learners.
WBITSs exhibit teacher-like behavior; previous studies have reported positive outcomes concerning the use of ITSs in educational activities [12, 30, 31, 15, and 16]. ITSs were used for various learning situations in physics education. Valeh and Lynch [33] used an ITS that identifies errors occurring in the steps of solving physics problems and provides clues about what the next step is. [21, 22, 23, 24, and 32] developed ITSs for teaching physics subjects.

Although internet- and computer-based education activities have limitations compared to classroom education, they offer advantages of time, space, rich content and so on. Koedinger et al. [34] discussed that although computer-based teaching systems are not suitable for group work, they are useful in self-learning. The advantages of internet- and computer-based tutoring systems over traditional education includes the freedom of individual perception, the privilege of access to information, equal learning opportunities, rich content and the availability of bridging. Traditional teaching and learning processes in education have been replaced by new and emerging technologies, modern technology has increased the access to information at home, and in workplaces and educational institutions; thus, education has become a long process [35].

Erdemir [26] used WBITSs in teaching physics subjects. In his research, preservice teachers taught the physics subjects of work, energy, and energy conservation using a WBITS and achieved positive outcomes concerning their academic performance. The availability of numerous examples, activities, animations, links to the subject, and conceptual processing-based problems, and the intelligence features within the WBITS, in comparison with traditional education, were effective in learning the subjects. The intelligent features of WBITSs include giving instant feedback to learners, allowing learners to resume where left off, no requirement to strictly follow learning pages, and the availability of numerous activities in the presentation of subjects. Additionally, WBITSs assess learners' level with exams in the relevant subjects, thereby allowing learners who reach the desired level to pass to the next subject. The deficiencies of learners who do not reach the desired learning level are identified by WBTISs. Then, these learners are directed to learning pages to restudy and make up their deficiencies so that they can retake exams until they pass. Teacher-like behavior of WBTISs increases the importance of using WBTISs in education.

\subsection{Using WBITSs in Teaching Physics Subjects to Support Classroom Educational and Instructional Processes and Eliminate Shortcomings Caused by Limited Class Hours}

In traditional classroom education, course contents must be taught in the classroom and within the scheduled time and individual perception, capacities are disregarded, thereby making it difficult for learners to keep up with the 
learning process. Scientific developments in the field of physics have caused new topics to emerge, thereby creating a need for more class hours to cover new topics during classes. This situation leads to challenges in the implementation of classes in line with their purpose. Such challenges encountered in classroom education can be reduced by using WBTISs for teaching basic physics subjects and details. The use of ITSs showing teacher-like behavior to teach physics subjects can provide access to a wide range of problems and rich contents, thereby supporting classroom education. Preservice mathematics teachers who taught physics subjects using a WBITS held the view that if the system is used in conjunction with classroom education, its effectiveness increases further [36]. WBITSs can be used for student modeling to teach subjects that cannot be addressed during classes or that cannot be discussed in detail. For example, WBITSs can be adapted for the purpose of solving problems and modeled to eliminate deficiencies. Because ITSs are composed of computer systems, artificial intelligence, and education support, modeling can be done for the purpose of use [12]. WBITSs can be adapted according to learners' perception, level of knowledge, and individual characteristics. WBITSs are advantageous systems that interact with learners (e.g. providing responses and feedback to learners), support the teaching of physics subjects in the classroom, and have long-term use and economic value. ITSs are high-quality teaching systems that can be used for different purposes according to learners' performance [37].

\subsection{Using WBITSs to Access Physics Topics without Time and Space Constraints and Offer Equal Training Opportunities}

Today it is possible to access a wide range of physics resources via the internet, such as e-books, lecture notes, problem solutions, virtual experiments, and animations. The feature that distinguishes a WBITS from other sources and tutoring systems is that it presents learning situations similar to classroom learning situations. WBITSs are computer programs, which allow modeling to provide individualized education based on learners' psychological status and are designed to help learners acquire cognitive and metacognitive knowledge relevant to their fields [38]. Systematic learning processes, rich contents, and intelligence make WBITSs advantageous. For example, WBITSs can identify learners' deficiencies and provide guidance to make up these deficiencies. They can comprehend and respond to learners' feedback. Additionally, they display teacher-like behavior such as assessing learners' level and passing to the next subject. The advantages of WBITSs in education processes can contribute to the teaching of physics subjects and offer educational opportunities for those who do not have formal educational opportunities.

\subsection{Using WBITSs in Teaching Basic Physics Subjects at University Level to Devote Greater Attention to Current Topics and Increase Practical (Experimental) Activities through the Teaching of Theoretical Subjects via the System}

Basic physics subjects at university level can be taught using WBITSs so that time allocated for current issues, experimental studies, and physics literacy can be enhanced. Prior to undergraduate physics subjects, secondary education basic physics subjects are presented to identify previous knowledge and create a background for new knowledge. For example, vectors, kinematics, electrical force, magnetic field, and mathematical operations are given before starting the undergraduate topics of mechanics and electricity. The topic vectors can be planned in an internet- and computer-based design and the content can be given by using WBITSs so that current issues related to technological developments can be discussed more detailed in classroom educational processes. WBITSs create opportunities to provide learners with advanced information about scientific and technological developments related to physics subjects. Advanced information supports the creation of new ideas, opinions, and projects, thereby stimulating innovation.

Theoretical aspects of physics can be taught through WBITSs and practical aspects of these subjects (e.g. experiments) are delivered in classroom educational processes. Effective learning processes can be achieved through practical experimental and research projects in classroom education, thereby promoting skills for scientific and technological developments. This situation can increase production-oriented practices and help satisfy the expectations of institutions and organizations for the integration of technological developments into education. Increasing practices related to technological developments in classroom physics education will be effective in meeting the needs of commercial organizations for qualified employees and will strengthen the ties between institutions and organizations.

\subsection{Using WBITSs in Teaching Physics Subjects Offline (Remote) to Control Learning Processes}

In internet-based (distance) education, it is hard to control learners, keep them engaged in classes and follow their learning process compared to traditional classroom education. The absence of teachers in internet-based (distance) education causes learners to act independently, lose their interest in courses, thereby making it difficult to run classes. The limitations of distance education include the lack of teacher-learner interaction [39], the lack of socialization and communication [40], and the low rate of regular attendance in web-based tutoring compared to traditional classroom education [11]. In addition, distance education processes lack practice-oriented (experimental) activities, thereby posing challenges to learners with poor 
self-learning skills [41]. These are disadvantages of distance educations. The intelligent features of WBITSs allow implementing controls such as checking whether learners have watched course contents and complete activities and tracking how many hours they have watched so that it can be assured that the entire learning process is completed. The use of WBITSs in distance physics education allows monitoring learning processes and offer feedback and rich contents, thereby helping heighten learners' interest in learning. The learning processes of distant education courses can be controlled and monitored through WBITSs. Given that WBITSs display teacher-like behavior, they comprehend learners' behavior and accordingly give feedback, thereby ensuring one-to-one interaction. Because WBITSs are modeled based on the programmed teaching method, they accordingly organize course contents and provide convenience for those who have poor self-learning skills. The limitations of offline education in physics topics can be reduced by using WBITSs.

\section{Discussion and Conclusions}

- Developments in technology and artificial neural networks and the interest of young people in technology have made it important to use WBITSs in undergraduate physics education. In addition, WBITSs have been among teaching systems used to satisfy expectations of internet-based teaching of physics subjects at undergraduate level. ITSs have been used in language education [46, 47 and 16], computer programming language $[42,43,44,45]$ mathematics education $[49,50,51]$ and physics education $[18,19,21,22,23,24,26,32,48]$. The interests of young people in technology, computer and technological advance, and advantages over traditional education have made the use of ITSs in physics education important. These factors have necessitated the use of WBITSs in physics education, which are among the internet- and computer-based ITSs.

- $\quad$ The use of WBITSs can be used to follow scientific developments in traditional (classroom) physics education and eliminate problems related to individual perception capacity and insufficient class hours. Additionally, rich contents, teacher-like behavior, and student-centeredness of WBITSs [30] support classroom physics education. Preservice teachers who used the system [36] confirmed the support of WBITS for classroom physics education.

- Online (remote) access to physics subjects via WBITSs contributes to equality of opportunity in education. The advantages of WBITSs including access to rich and flexible course contents, instant feedback, and the control and follow-up of course processes make WBITSs more effective compared to other distance learning situations.

- The content of basic physics subjects at undergraduate level is presented to learners using WBITSs so that current issues related to technological developments can be addressed during classroom educational processes. WBITSs create opportunities for advanced information about scientific and technological developments related to physics subjects. Innovations can be developed through the promotion of the creation of new ideas and projects. If theoretical aspects of physics subjects are taught through WBITSs and practical aspects are addressed in classroom educational processes, it offers many benefits such as promoting skills for scientific and technological advances and time-, economy, and work-related gains.

WBITSs can be used to remove the limitations of distance physical education, keep learners engaged, provide feedback, and control educational processes. Distance teaching of subjects becomes more effective with the use of WBITSs in physics education.

\section{REFERENCES}

[1] Alhabbash, M., Mahdi, A. O., Abu Naser, S. S. (2016). An Intelligent Tutoring System for Teaching Grammar English Tenses. European Academic Research - Vol. IV, Issue 9. https://www.researchgate.net/publication/311843483_An Intelligent_Tutoring_System_for_Teaching_Grammar_En glish_Tenses

[2] Batagan, R., Boja, C., Cristian. (2011). Intelligent Educational Systems, Support for an Education Cluster. Available from: https://www.researchgate.net/publication/ 228399544_Intelligent_educational_systems_support_for an_education_cluster [accessed Oct 16 2018].

[3] Anderson, T., \& Dron, J. (2011). Three generations of distance education pedagogy. The International Review of Research in Open and Distance Learning, 12(3), 80-97. Retrieved from. http://www.irrodl.org/index.php/irrodl/arti cle/view/890

[4] Moore, M., \& Kearsley, G. (2005). Distance Education: A System View. Canada: Wadsworth.

[5] Urdan, T. A. \& Weggen, C. C. (Ed) (2000). Corporate e-learning: Exploring a new frontier, International Journal of Instructional Technology and Distance Learning, 1(9), 21-31.9.

[6] Carswell, A. D., \& Venkatesh, V. (2002). Learner outcomes in an asynchronous distance education environment. International Journal of Human-Computer Studies, 56(5), 475-494.

[7] Brusilovsky, P., Eklund, J., and Schwarz, E. (1998). Web-based education for all: A tool for developing adaptive courseware. Computer Networks and ISDN Systems. 30, 1-7, 291- 300 . 
[8] Unesco. (2002)." Open and Distance Learning" Trend, Policy and Strategy Considerations, s. 64.

[9] Tzouveli, P., Mylonas, P ve Kollias, S. (2008). An intelligent e-learning system based on learner profiling and learning resources adaptation. Computers \& Education, 51, pp. 224-238.

[10] Doherty, W. (2006). An analysis of multiple factors affecting retention in web-based community college courses. The Internet and Higher Education, 9(4): 245-255.

[11] Carr, S. (2000). As distance education comes of age, the challenge is keeping the students. The Chronicle of Higher Education, 46(23), A39 - A41.

[12] Jerinic, L. (2013). Computer based education -twenty years of promises, but http://academia.edu/2546929/Computer Based_Education_Twenty_Years_of_Promises_But.

[13] Canfield, W. 2001. "ALEKS: A Web-based intelligent tutoring system". Mathematics and Computer Education, vol. 35 , no. 2, pp.152-158.

[14] Nye. B., D. (2015). Intelligent Tutoring Systems By and For the Developing World: A Review of Trends and Approaches for Educational Technology İn a Global Context. International Journal of Artificial Intelligence in Education. Volume 25, pp. 177-203. DOI 10.1007/s40593-014-0028-6.

[15] Moundridou, M., \& Virvou, M. (2000). A web-based authoring tool for algebra-related intelligent tutoring systems. Educational Technology \& Sociey, 3(2), 61-70.

[16] Karacı, A. (2013). Ses sentezleme ve tanıma teknolojilerini kullanarak türkçenin ana dil olarak öğretimi için zeki öğretim sistemi geliştirilmesi, Doctoral thesis, Gazi Üniversitesi Bilişim Enstitüsü, Ankara, 17.

[17] İstanbul, A. (2003). Biyomedikal mühendisliği eğitimi için yazılım geliștirme. Unpublished $\mathrm{PhD}$ Thesis, Gazi Üniversitesi Fen Bilimleri Enstitüsü, Ankara.

[18] Van-Lehn, K \& Lynch. C. (2005). The Andes Physics Tutoring System: Lessons Learned" International Journal of Artificial Intelligence in Education 15, 147-204.

[19] Young-Jin. L. (2011). Utılızıng formative assessments to guide student learning in an interactive physics learning environment. J. Educational Technology Systems, 39(3), 245-260. doi.10.2190/ET.39.3.c.

[20] Myneni, L., Narayanan, N. H., Rebello, S., Rouinfar, A \& Puntambekar, S., (2013). An interactive and intelligent learning system for physics education. Ieee Transactions On Learning Technologies, 6(3), 228-239.

[21] Albacete, P, L. (1999). An intelligent tutoring system for teaching fundamental physics concepts. Dissertations University of Pittsburgh.

[22] Chakraborty, S., Roy, D., \& Basu, A. (2010). Development of knowledge based intelligent tutoring system. In Advanced knowledge based systems: Model, applications. (Eds. Sajja \& Akerkar), 74-100.

[23] Chi, M., \& VanLehn, K. (2010). Meta-cognitive strategy instruction in intelligent tutoring systems: how, when, and why. Educational Technology \& Society, 13(1), 25-39.
[24] Mills, C., \& Dalgarno, B. (2007). A conceptual model for game-based intelligent tutoring systems. In ICT: Providing choices for learners and learning. Proceedings ascilite Singapore, 692-701.

[25] Stathacopoulou, R., Magoulas, G.D. \& Grigoriadou, M. (1999). Neural network-based fuzzy modeling of the student in intelligent tutoring systems. Neural Networks, International Joint Conference on, 5, 3517 - 3521.

[26] Erdemir, M. (2015). İnternet Tabanlı Bir Zeki Öğretim Sisteminin Fizik Eğitimine Uyarlanması ve Uygulanması. Doctoral thesis, Gazi Üniversitesi Eğitim Bilimleri Enstitüsü, Ankara.

[27] [APUS. (2019). American Public University System. https://apus.libanswers.com/writing/faq/2193

[28] We Are Social, (2019).https://wearesocial.com/blog/2018/ 01/global-digital-report-2018 26.02.2019. reached on.

[29] TurkStat. (2019). Türkiye İstatistik Kurumu.

[30] Rosic, M., Galavinic, V ve Stankov, S. 2006). Intelligent Tutoring Systems for the New Learning Infrastructure. DOI: 10.4018/9781591405030.ch008.

[31] Doğan, N. \& Kubat B. (2008). Akıllı öğretim sistemleri için yeni bir bileşen: düzenleyici modül. Bilişim Teknolojileri Dergisi, 1(2), 5-9.

[32] Stathacopoulou, R., Magoulas, G.D. \& Grigoriadou, M. (1999). Neural network-based fuzzy modeling of the student in intelligent tutoring systems. Neural Networks, International Joint Conference on, 5, 3517 - 3521.

[33] Van-Lehn, K \& Lynch. C. (2005). The Andes Physics Tutoring System: Lessons Learned" International Journal of Artificial Intelligence in Education 15, 147-204.

[34] Koedinger, K. R., Anderson, J. R., Hadley, W. H., and Mark, M. A. (1997). "Intelligent Tutoring Goes To School in the Big City," International Journal of Artificial Intelligence in Education 8: 30-43.

[35] Bhakta, K and Dutta, N. (2016). Impact of Information Technology on Teaching-Learning Process. International Research Journal of Interdisciplinary \& Multidisciplinary Studies (IRJIMS). A Peer-reviewed Monthly Research Journal ISSN: 2394-7969 (Online), ISSN: 2394-7950 (Print) Volume-II, 131-138. http://www.irjims.com

[36] Erdemir, M., İngeç, Ş.\& Karacı, A. (2016) "Student Vıew On Web-Based Intelligent Tutoring Systems About Success And Retention Of Physics Education”. International Journal of Managing Public Sector Information and Communication Technologies (IJMPICT) Vol. 7, No. 2.

[37] Encheva, S. \& Tumin, S. (2005). Cooperative Shared Learning Objects in an Intelligent Web-Based Tutoring System Environment. CDVE 2005, Lecture Notes in Computer Science, Springer Verlag, 227-234.

[38] Ma, W., Adesope, O. O., Nesbit, J. C., Liu, Q. (2014). Intelligent tutoring systems and learning outcomes: $\mathrm{A}$ meta-analysis. Journal of Educational Psychology, 106, 901-918. doi: 10.1037/a0037123.

[39] Chyung, Y., Winiecki, D. J., \& Fenner, J. A. (1998). A case study: Increase enrollment by reducing dropout rates in adult distance education (ERIC Document Reproduction 
Service No. ED 422 848).

[40] Rovai, A.P. (2001). Classroom community at a distance: a comparative analysis of two ALN-based university programs. Internet and Higher Education, 4, pp. 105-118.

[41] Kaya, Z. (2002). Uzaktan Eğitim. Pegem. A Yayıncılık. Ankara.

[42] Abu -Naser, S.S. (2008). Developing an intelligent tutoring system for students learning to program in $\mathrm{C}++$. Information Technology Journal, 7:7, 1055-1060.

[43] Weber, G \& Brusilovsky, P. (2001). "ELM-ART: An adaptive versatile system for web-based instruction", International Journal of Artificial Intelligence in Education, $12,351-384$.

[44] Mitrovic, A. (2002). NORMIT, a web-enabled tutor for database normalization. Proceedings of the International Conference on Computers in Education (ICCE 2002), Auckland, 1276-1280.

[45] Suraweara, P. (2001). An intelligent teaching system for database modelling. Msc Thesis, Computer Science at the University of Canterbury.

[46] Carbonell, J. R. (1970). AI in CAI: An artificial intelligence approach to computer-assisted instruction, IEEE Transactions on Man-Machine Systems, 11 (4), 190-202.

[47] Martins, V. F., Satoshi, A. L \& de Oliveira Neto, J. S. (2008). Utilization of fuzzy theory in the modeling of users of adaptive hypermedia systems, First International Conference on Advances in Computer-Human Interaction, Martinique, 290-296. doi: 10.1109/ACHI, 32.

[48] Bahceci, F. \& Gurol, M. (2010). Eğitimde akıllı oğretim sistemleri uygulamalarına yonelik bir model onerisi, International Educational Technology Conference, Boğazici University, İstanbul-Turkey, 464-467.

[49] Graff, M., Mayer, P. \& Lebens, M. (2008). Evaluating a web based intelligent tutoring system for mathematics at German lower secondary schools. Educ Inf Technol, 13, 221-230. Doi 10.1007/s10639-008-9062.

[50] Beal, C. R., Arroyo, I., Cohen, P. R., \& Woolf, B. P. (2010). Evaluation of Animal Watch: An Intelligent Tutoring System for arithmetic and fractions. Journal of Interactive Online Learning, 9, 64-77.

[51] Santhi, R., Priya, B., \& Nandhini, J.M., (2013). Review of intelligent tutoring systems using bayesian approach. Papaer presented in National Conference on Computational Linguistics and Integrated Classical Knowledge. 